\title{
Nature Conservation - achievements and challenges within its first four years
}

\author{
Klaus Henle', Pavel Stoev², Lyubomir Penev² \\ I UFZ - Helmholtz Centre for Environmental Research, Department of Conservation Biology, Leipzig, Germany \\ 2 Pensoft Publishers, Sofia, Bulgaria \\ Corresponding author: Klaus Henle (klaus.henle@ufz.de)
}

Received 6 April 2016 | Accepted 6 April 2016 | Published 13 April 2016

http://zoobank.org/8911F335-B570-4758-84A4-F2D173689D64

Citation: Henle K, Stoev P, Penev L (2016) Nature Conservation - achievements and challenges within its first four years. Nature Conservation 14: 1-5. doi: 10.3897/natureconservation.14.8773

To be effective, research on natural resource management and conservation must be communicated to practitioners involved in hands-on conservation efforts and to policy makers. However, the results of scientific research are often not readily applied in management. Likewise, many applied conservation schemes do not reflect current research knowledge. The "knowledge-implementation-gap" (Knight et al. 2008) is becoming increasingly obvious. As a consequence, the $10^{\text {th }}$ Party of the Convention on Biological Diversity, in Nagoya held in October 2010, identified a strengthened link between science and policy as an explicit target (http://www.cbd.int/sp/targets/). This requires new alliances between science, economics, policy makers, and natural resource managers (Briggs and Knight 2011).

Four years ago the journal Nature Conservation was established to address these challenges (Henle et al. 2012). It had and still has as a major goal to support synergistic interactions among scientists, policy-makers and managers. This is a practical task. The knowledge base of conservation biologists is already extensive, and the numbers of experienced practitioners are increasing around the world. The task is to bring different specialists together and create a forum that supports knowledgeable practices, and to learn from the experience - successes and failures - of all parties. The journal specifically aims at strengthening the link between science, policy and management by publishing timely, innovative papers with clear practical relevance.

Copyright Klaus Henle et al. This is an open access article distributed under the terms of the Creative Commons Attribution License (CC BY 4.0), which permits unrestricted use, distribution, and reproduction in any medium, provided the original author and source are credited. 
Strengthening the link between science, policy and management is not only a major challenge for applied biodiversity conservation (Carmen et al. 2015) but also for journals, especially new ones. Scientists are primarily rewarded for the number of publications in international journals with high impact factors (Alberts 2013). However, many of these journals are not accessible to those working in nature conservation management or policy. Achievements in the transfer of knowledge from science to policy and applied nature conservation are more difficult to measure. These difficulties were faced initially also by Nature Conservation. In the first three years it was challenging to obtain a sufficiently larger number of articles that were both scientifically of high quality and at the same time highly relevant for nature conservation.

Despite these challenges Nature Conservation managed to publish 12, 13, and 13 articles in 2012, 2013, and 2014. The number grew to 21 in 2015, and after the acceptance for tracking by two of the largest abstract and citation databases of peerreviewed literature Thomson Reuters' Web-of-Science and Scopus, the number of submissions has recently increased. The rejection rate in the first four years was $60 \%$. Most of the published articles were research articles (Fig. 1). Although there is some geographic bias in the submission of articles, we are proud that the geographic origin of authors is very broad, already comprising authors from 38 countries (Fig. 2). An overview of the most productive authors can be found at http://natureconservation. pensoft.net/most_productive_authors.

The two most frequently viewed articles published in the first four years is by van Sway et al. (2012) on the Dos and Don'ts for the butterflies of the Habitats Directive of the European Union (viewed 17978 times) and by Kideghesho et al. (2013) on

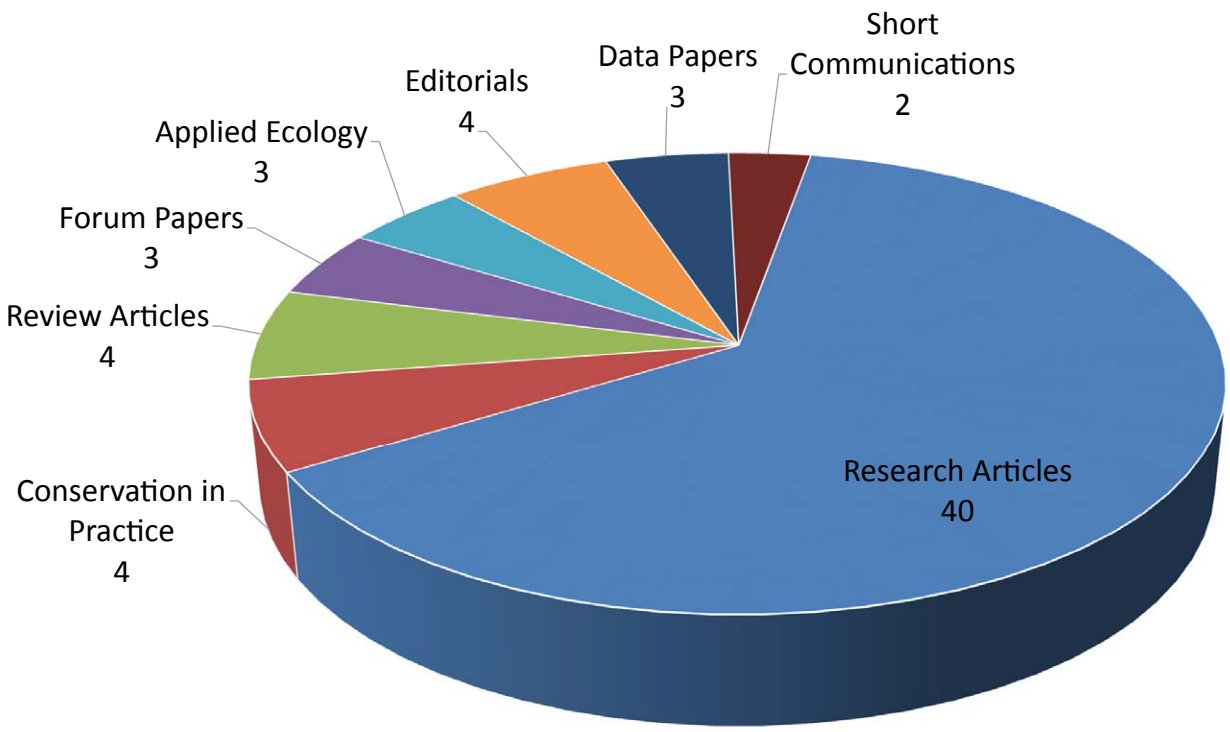

Figure I. Distribution of published articles by type. 


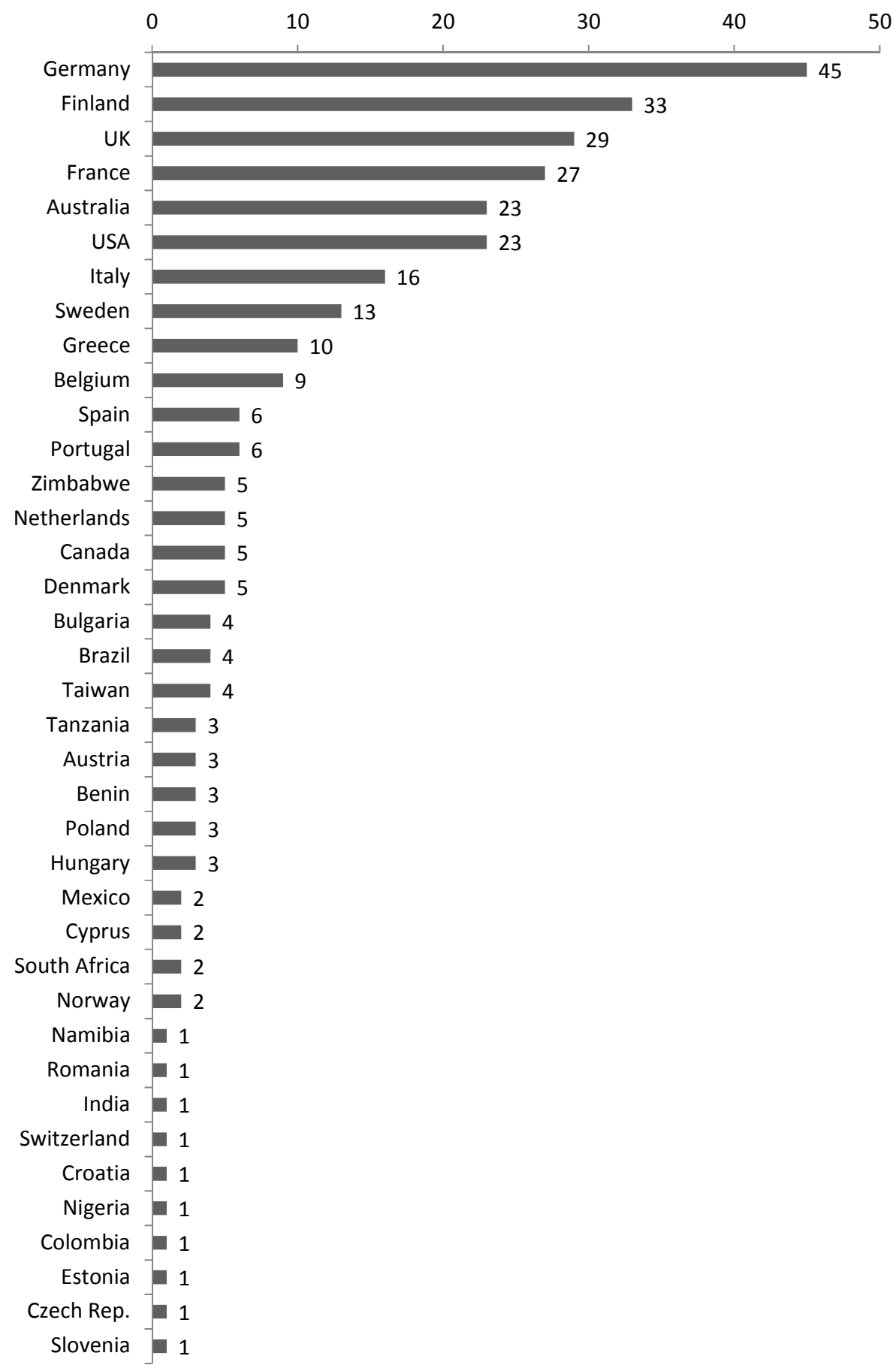

Figure 2. Distribution of authors by origin. 
challenges in biodiversity conservation in Tanzania (viewed 14384 times). A further list of frequently viewed articles can be found at http://natureconservation.pensoft.net/ browse_journal_articles?sortby $=1$. The large number of views indicate that these papers are viewed also by those working in or interested in applied nature conservation.

Nature Conservation specifically facilitates authors in generating impact in applied nature conservation. The Public Relations team of Pensoft supports authors in generating news stories on papers that appeared in Nature Conservation. For example, news stories on the illegal trade of the Indian star tortoises were published, among others, in The Guardian, National Geographic, Science News Magazine. The butterfly publication of van Sway et al. (2012) was featured in the European Research and Development Information Service (CORDIS). Similarly, press releases on Eurekalert obtained high numbers of views by science journalists e.g., "Aging nestling Carnaby's cockatoo, Calyptorhynchus latirostris, and estimating the timing and length of the breeding season" (2,932 views) and "A critical review of the Mediterranean sea turtle rescue network: a web looking for a weaver" (2,612 views).

Quality journals cannot exist without authors profiting from publishing in the journal and without the voluntary work of reviewers and editors. We are deeply grateful to all the reviewers and editors (named at http://natureconservation.pensoft.net/ most_active_reviewers and http://natureconservation.pensoft.net/most_active_editors) that helped achieving a timely evaluation of all published articles.

We hope that our readers enjoy the publications in Nature Conservation and will consider submitting manuscripts that may make a difference for biodiversity policy and management and nature conservation at large.

\section{References}

Alberts B (2013) Impact factors distortions. Science 340: 787. doi: 10.1126/science.1240319 Briggs SV, Knight AT (2011) Science-policy interface: scientific input limited. Science 333: 696-697. doi: 10.1126/science.333.6043.696-b

Carmen E, Nesshöver C, Saarikoski H, Vandewalle M, Watt A, Wittmer H, Young (2015) Creating a biodiversity science community: Experiences from a European Network of Knowledge. Environmental Science and Policy 54: 497-504. doi: 10.1016/j.envsci.2015.03.014

Henle K, Bell S, Brotons L, Clobert J, Evans D, Goerg C, Grodzinska-Jurcak M, Gruber B, Haila Y, Henry P, Huth A, Julliard R, Keil P, Kleyer M, Kotze D, Kunin W, Lengyel S, Lin Y, Loyau A, Luck G, Magnuson W, Margules C, Matsinos Y, May P, Sousa-Pinto I, Possingham H, Potts S, Ring I, Pryke J, Samways M, Saunders D, Schmeller D, Simila J, Sommer S, Steffan-Dewenter I, Stoev P, Sykes M, Tóthmérész B, Yam R, Tzanopoulos J, Penev L (2012) Nature Conservation - a new dimension in Open Access publishing bridging science and application. Nature Conservation 1: 1-10. doi: 10.3897/natureconservation.1.3081

Kideghesho JR, Rija AA, Mwamende KA, Selemani IS (2013) Emerging issues and challenges in conservation of biodiversity in the rangelands of Tanzania. Nature Conservation 6: 1-29. doi: 10.3897/natureconservation.6.5407 
Knight AT, Cowling RM, Rouget M, Balmford A, Lombard AT, Campbell BM (2008) Knowing but not doing: selecting priority conservation areas and the research-implementation gap. Conservation Biology 22: 610-617. doi: 10.1111/j.1523-1739.2008.00914.x

Van Swaay C, Collins S, Dušej G, Maes D, López Munguira M, Rakosy L, Ryrholm N, Šašić M, Settele J, Thomas JA, Verovnik R, Verstrael T, Warren M, Wiemers M, Wynhoff I (2012) Dos and Don'ts for butterflies of the Habitats Directive of the European Union. Nature Conservation 1: 73-153. doi: 10.3897/natureconservation.1.2786 